\title{
The Research on Present Status of Straw Ash as High Performance Concrete Admixture
}

\author{
Zhengjun WANG \\ Heilongjiang University \\ Harbin, China \\ e-mail:wzjsir@163.com
}

\author{
Qinghui LAI \\ Heilongjiang University \\ Harbin, China \\ e-mail: 18765855696@163.com
}

\author{
Kang HAO \\ Heilongjiang University \\ Harbin, China \\ e-mail: 498555667@qq.com
}

\begin{abstract}
With wide application of the high performance concrete in Engineering, the research and application of high performance concrete admixture are attaching more and more attention by researchers. Although researches are more mature on the aspects of fly ash, slag, silica fume and other non-biological materials, the research is behindhand in the aspect of biological material such as straw ash, which contains a large amount of silica dioxide and has a certain amount of volcanic ash activity. It is considered that Heilongjiang Province as a major agricultural province, moreover, burning straw pollution is particularly serious in summer and fall. It is beneficial to manufacture straw ash high performance concrete and improve the strength and durability of the concrete. According to recent analysis on physical and chemical properties of the straw ash, it is completely feasible to improve the strength and durability of the concrete by adding straw ash to it in a reasonable method. It can be sure that, if after in-depth research, the straw ash as a concrete admixture would have a wide foreground in the future.
\end{abstract}

Keywords-straw ash; high performance concrete (HPC); strength; durability

\section{INTRODUCTION}

Straw is a general term of the stem and leaf of mature crops. It is a kind of multipurpose renewable biological resource. China is a vast agricultural country, according to statistics, the rice production of China in 2013 was 202 million tons, accounting for $19 \%$ of the total planting [1] area of the world, furthermore, straw resources are more abundant, the annual output up to 600 million tons. Except a small part for the paper and sheet processing, most of the straw resources are abandoned or burned in situ. It is very common that farmers burn straw in every harvest season, at least one third of straw was burned by this way. It could be imaged that the pollution is extremely serious. Burning straw not only occupies the land, but also produces a large number of harmful substances, which is extremely harmful to the environment, people and other animals [2]. The amount of straw which could be utilized as energy is nearly 0.2 billion tons, could at least alternative 0.1 billion tons of coal biomass fuel with zero $\mathrm{CO} 2$ emission characteristics.
Hence, the biomass fuel power generation will become one of the most important ways to develop "low-carbon economy" around the world [3]. The development of straw power generation [4] has huge potential as long as utilizing this technology in rational way. More importantly, the emissions of power plant from combusting waste straw and ash are valuable. The development of power plants, which utilizing straw to generate electricity is fast in China. The straw contains a large amount of $\mathrm{SiO}_{2}$; other ingredients are volatile when burning straw, which leaves a much $\mathrm{SiO}_{2}$ in straw ash. Most of the straw ash is powdery, and contains a certain amount of burnt and fused small pieces. The straw ash particles has no fixed shape, the surface area is generally larger than that of cement and slag. It has a certain volcanic ash activity [5-6], and it could improve the performance of concrete by replacing partial cement in concrete.

In this paper, some research on straw ash as one of the concrete mineral admixture is introduced. Through the research of the physical and chemical properties of straw ash and the current problems existing in the development of straw ash, we could further improve the performance of straw ash adding into concrete.

\section{STUDY ON PHYSICAL AND CHEMICAL PROPERTIES OF STRAW ASH}

Straw contains a certain amount of $\mathrm{SiO}_{2}$, under the condition of high temperature combustion, would leave rich $\mathrm{SiO}_{2}$ straw ash, which has a certain volcanic ash activity [7-8]. With the increase of combustion temperature, the quantity of the straw burning ash would gradually reduce. Under the same temperature, the rice straw ash is significantly higher than corn and sunflower straw ash amount. With the increase of the burning temperature [4], straw carbon and volatile combustion gradually disappear, straw alkali metal deposited amount increases with increasing incineration temperature [9 10]. A large number of studies have shown that this organism gray surface is relatively bigger, Le et al [8] have shown that the pattern of wheat straw ashes which distribute like chain are different from rice and corn straw ashes. The corn straw ashes are 
similar to sphere and distribute well, their particle size is between $50-100 \mathrm{~nm}$. The particle size of rice straw ashes is smaller which is about $40 \mathrm{~nm}$. The results of TEM show that the straw ashes are nano-particles with various morphologies. El-Sayed et al [12] analyzed the rice straw ash and found that specific gravity of rice straw ash is 2.25 and the surface area is $18460 \mathrm{~cm} 2 / \mathrm{g}$.

According to the corn straw combustion test executed by Li huiyuan et al [13], the combustion could be roughly divided into three processes, including water vaporing, volatile combustion, fixed carbon and residual volatile combustion. The first period: $0 \sim 120^{\circ} \mathrm{C}$, evaporation of water in the raw material; the second period: $230 \sim 340^{\circ} \mathrm{C}$, showing the analysis of volatile raw materials and combustion; the third period: $420 \sim 510^{\circ} \mathrm{C}$, fixed carbon and residue begin to burn. When the temperature increases to $510^{\circ} \mathrm{C}$, combustible components would burn out, which means the quality would not change. Liu qiaoling et al [14] found that when the rape straw is washed, under the condition of $500^{\circ} \mathrm{C}$, the $\mathrm{SiO}_{2}$ content of calcination could increase up to $61.76 \%$, the ash possesses hydration activity. NBiricik et al [7] [15] found that when the wheat straw is roasted 5 hours under $570 \sim 670^{\circ} \mathrm{C}$, the $\mathrm{SiO}_{2}$ content of the ashing composition could reach up to $73 \%$. Straw ash has certain volcanic ash activity, when added into concrete; this could improve compressive strength of concrete performance.

\section{III.STRAW GRAY CONCRETE RESEARCH RESULTS AND THE STATUS QUO}

Yue Qiang and Jiang Sheng [16] use 4\% of the straw ash to replace the same quality of cement cementitious materials to prepare the high performance concrete. The strength of the sample with $20 \%$ straw ash and the sample without straw ash is same. At the same time, it could be figured out that the dispersion degree of $\mathrm{SiO}_{2}$ in straw ash is relatively large and it has a high degree of volcanic ash activity. The straw ash contains high potassium and sodium, which is helpful to the hydration reaction of slag. With the deepening of the hydration reaction of slag could improve the strength of the solidified slurry of cement or concrete. The volume instability caused by the alkali expansion is reduced [17]. Studies have indicated that the strength of the Autoclaved cement mortar would improve when added with straw ash. The strength of the ash motor would have a certain improve when added with straw ash under the condition of low concentration of magnesium sulfate and sodium sulfate, but the flexural strength would reduce. The straw ash content should not exceed $24 \%$ [18].

Liu qiaoling [19] adds rape straw ash substitute an equal amount of cement into concrete. In addition, the rape straw ash is generated during the process of hydraulic test. Testing the apparent density, compressive strength and $\mathrm{PH}$ value when the $\mathrm{SiO}_{2}$ which contained in the concrete is under the condition of best ashing activity. According to the study, Zhang qiang [20] found that straw ash high performance concrete has a lower strength in early time. Silicon powder possesses higher ash activity and filling effect. Testing the mechanical properties and workability of the double mixing cement under the condition of adding moderate amount of straw ash and different amount of silicon powder. The results show that with the increase of silicon powder, the concrete work performance gradually improves, when the amount of the silicon powder is $10 \%$, the compressive strength of concrete increase by $24 \%$. However, because of the high cost, of the silicon powder, it would be better for future researchers to pay more attention on utilizing rice husk ash, fly ash and other alternatives to reduce the cost of the concrete. They also prepared rape straw ash concrete specimens [14] to analyze the impact of rape straw ash has on concrete tensile properties. The results show that when the content is $5 \%$, the straw ash high performance concrete is almost same with the standard concrete. When the ash content exceeds $10 \%$, the tensile strength of the straw ash has a larger decline. Hence it is not suitable for using in high strength concrete.

Through adding a certain amount of straw ash into concrete to prepare high strength concrete, Chen Chao found that adding right amount of straw ash would improve the strength of the concrete in early times. When proportion of the straw ash of the concrete is $5 \%$, the $3 \mathrm{~d}$ concrete compressive strength of the high performance would dramatically improve; other early strengths of the concrete also improve to some extent. The impact that straw ash concrete has on the later strength is not obvious, but the strength decreased slightly. Thus, to some extent, straw ash could improve the early strength of the concrete, but has little effect on the late strength.

\section{STRAW ASH High PERFormanCE CONCRETE PROBLEMS}

(1) Increasing the content of $\mathrm{SiO}_{2}$ in straw ash and possessing hydration activity. It also found that burning straw ash has the nature of strong alkaline, prone to corrosion of metal.

(2) Chen chao [9] et al found that the potassium content of straw ash reached $14.72 \%$. In addition, calcium, magnesium, sodium, phosphorus is also a considerable content, these elements present in the concrete in the form of salts. As time passes, there will be a "salting out" phenomenon, the latter surface will produce a layer of "white spots" which might result sand or flaking.

(3) Adding large amount of straw ash would seriously affect entraining mortar workability and weak entraining mortar consistency. Fresh mortar appears "instantaneous condensate" trend.

(4) Straw ash contains a certain amount of fixed unburned carbon and stable nature. Higher levels of unburned carbon generally would not be involved in a chemical reaction. This might decrease entraining mortar strength.

\section{Straw ASH High PERFORMANCE CONCRETE EXPECTATIONS FOR FUTURE RESEARCH}

(1) Strictly controlling the acquisition process of crop straw ash, controlling straw ash composition quality, improving the technique in producing ash, reducing the content of alkali metal straw in the ash, avoiding "salting 
out" phenomenon in concrete, and affecting the quality of the concrete.

(2) We should improve the specific practicability of concrete with high straw ash and high performance, optimize the technical and structural design method and technology mix of technological innovation - particularly to enable the performance of the daily use of moderate concrete to be strengthened and further develop the range of practical use in the field of straw concrete.

(3) In accordance with the conditions of elevated straw ash concrete strength grade, it should improve the preparation of concrete technology, further study the advantages and high-performance of straw ash in the natural environment, ensure that it is suitable for large-scale structure and reliable high-rise buildings, tunnels, road, ports, dams and rationality.

\section{ACKNOWLEDGMENT}

The paper was supported by science and technology project of Heilongjiang sanjiang engineering construction administration (HGZL/KY-01).

\section{REFERENCE}

[1] Li Zhenhuai, Li Zhengguo, Tang Pengqin. Spatial-temporal changes of rice area and productionin China during 1980-2010 [J] ACTA GEOGRAPHICA SINICA, 2013, 68(5): 680-693.

[2] http://www.pm25.com/news/161.html

[3] Liu dianzhong, YuYing et al. Design of the Mix-proportion About of Concrete Material Properties of Straw [J]. Jouenal of Jilin Institutes of Architecture, 2010. 27(1):19-21.

[4] Liu Mingda, Xiao Zhijing, Wang houxin. Effect on the content and availability nutrient in straw ash under the high temperature [J]. Renewable Resource, 2009, 27(3): 46-52.

[5] Chen Chao, Huang Kuaizhong. Effects of straw ash on the property of concrete [J]. Ready-mixed Concrete, 2014, 7:27-30.

[6] Liu qiaoling, LI baohua. Review of Straw-Based Building Materials [J]. Biological Disaster Science, 2013. 36, (4): 448-450.

[7] Hasan Biricik, Fevziye Akoz. Study of pozzolanic properties of wheat straw ash [J]. Cement and Concrete Research, 1999, 29: 637-643.
[8] Le Yuan, Li Longshe. Study on combustion characteristics of biomass [J]. Energy engineering, 2006, (4): 30-33.

[9] Lang fang, Ma Xiaoqian, Wang Jingjing. Study on the ash characteristics of stalks [J]. Renewable Energy Resources, 2007(4): 25-28.

[10] Tang Yanling, Yu Chunjiang, Fang Mengxiang. Inorganic material determination and distributing in biomass [J]. Journal of Chemical fuel, 2005(1): 190-193.

[11] Nabil M.Al-Akhras, Bilal A. Abu-Alfoul. Effect of wheat straw ash on mechanical properties of autoclaved mortar [J]. Cement and Concret Research, 2002, 32: 859-863.

[12] IYER R S, SCOTT J A, Power station fly ash-a review of value-added utilization outside of the construction industry [J]. Resources, Conserva-tion and Recycling, 2001, 31(3): 217-228.

[13] Li Huiyuan, Huang Siwei, Zhou Dingguo. Comprison of properitis for corn straw with and without pith. Journal of Zhejiang University, 2013, 30 (2): 251-256.

[14] Zhang Qiang. Performance test on the rape straw concrete [D] Changsha: Master's Degree Thesis of Hunan Agricultural University, 2014

[15] Zhang Qiang, Liu Baohua, Liu Qiaoling et al. Influence of ashing conditions on the ash characteristics of rape straw [J]. Journal of Hunan Agricultural University (Natural Sciences), 2013, 39(1):107-110

[16] Yue Qiang, Jiang Sheng. Test using straw ash as cement admixture [J]. Cament, 2009, 11:4-5.

[17] Backharev T, Sanjayan J G, Cheng Y-B. Resistance of alkali -activated slag concrete to alkali-aggregate reaction $[\mathrm{J}]$. Cement and Concrete Research, 2001(31):331-334.

[18] Hasan Biricik, Fevziye Akoz. Resistance to magnesium sulfate and sodium sulfate attack of mortars containing wheat straw ash [J] Cement and Concrete Research2000, 30:118 9-1197.

[19] Liu Qiaoling. Study on the characteristics of straw-based concrete [D]. Master's Degree Thesis of Hunan Agricultural University, 2013.

[20] Zhang Qiang, Liu Baohua, Liu Qiaoling et al. Effect of rape straw ash and silica fume admixture on concrete performance [J]. Journal of Hunan Agricultural University (Natural Sciences), 2014, 40(3): 334-336.

[21] Ju Cheng, Wang Tao, Sun Pengfei. Research on the Effects of Energy Saving Mortar Cement Base Bleed Air Mixed with Straw Ash [J]. Journal of Jiamusi University (Natural Science Edition), 2015(4): 609-612. 